\title{
STUDIES ON THE EXPERIMENTAL GASTROINTESTINAL ULGERS PRODUGED BY RESERPINE AND STRESS I. RELATIONSHIP BETWEEN PRODUCTION OF ULCERS AND CHANGES IN TISSUE MONOAMINES
}

\author{
MASAMI DOTEUCHI \\ Division of Neuropharmacology, Shionogi Research Laboratory, Shionogi \& Co., Ltd., Fukushima-ku, Osaka
}

Received for publication June 5, 1967

In recent years a number of methods for producing psychogenic ulceration have been reported. Ulcers could be formed by treatment with reserpine combined with stress such as restraint(1), conflict (2), electrical stimulation of the hypothalamus (3), and electrical shock through a grid in the floor (4). Kido (4) has described production of ulcers in cats by exposure to stress such as electrical or mechanical shock after the tissue monoamines had been exhausted by reserpine treatment. When the stress was given during the release of monoamines by reserpine no ulcer could be formed. This shows that monoamines such as serotonin and norepinephrine are involved in the formation of ulcers.

The present paper describes 1) the cellular localization of serotonin and norepinephrine in the gastrointestinal tract of cats by the method developed by Carlsson et al. $(5,6), 2$ ) correlation between manoamine contents and ulcer and 3) the role of stress in the formation of ulcers.

\section{METHODS}

Cats of both sexes weighing from 2.5 to $4.0 \mathrm{~kg}$ were used. These animals were divided randomly into five groups. All animals were deprived of food for 16 hours previous to the experiments. The first group was not treated. The second group was administered reserpine in various doses. The third group was placed in experimental cages and 5seconds electrical shocks were given every 30 seconds for 24 hours to their body surfaces through stainless steel grids situated in the floor (abbreviated as grid shock). The intensity of grid shock was adjusted so that the shock always elicited invariable emotional responses such as rage, fear and attempt to escape from the cage. The fourth group was given 4 hours grid shocks, 20 hours after the administration of $0.1 \mathrm{mg} / \mathrm{kg}$ of reserpine. The fifth group was vagotomized and splanchnectomized and these cats were treated similar to the fourth group. Vagotomy at the cervical level and splanchnectomy were undertaken under pentobarbital anesthesia five days before the experiments.

At the end of the experiments all animals were sacrificed by decapitation under pentobarbital anesthesia, stomachs with an adjoining $15 \mathrm{~cm}$ of duodenum were removed, cut 
along the greater curvature and then photographed. Small pieces of tissue for histochemistry were removed immediately after decapitation and frozen in a mixture of acetone and solid $\mathrm{CO}_{2}$. They were dried in vacuo at temperatures between $-20^{\circ} \mathrm{C}$ and $-35^{\circ} \mathrm{C}$ for a week, treated with formaldehyde gas at $80^{\circ} \mathrm{C}$ for 60 minutes, embedded in paraffin, sectioned at 6 to $9 \mu$ and mounted in non-fluorescent liquid paraffin.

Fluorescence microscopy was performed with a Zeiss fluorescence microscope with an Osram HBO 200 high pressure mercury lamp, fitted with a BG 12 filter. A darkfield condensor for immersion oil was used and the secondary filter was a Zeiss " 50 " filter. A Nikon fluorescence microscope with a Toshiba SH200 high pressure mercury lamp, BV2 and Y51. filters, was also used.

After removing pieces for histochemistry, gastrointestinal tract was fixed in $10 \%$ formalin and examined histologically. The severity of ulceration was estimated by the grading method developed by Kido (4); that is, no change $=0$, erosion $=1$, single mucosal defect $=2$, multiple mucosal defects $=3$, single mucosal defect to muscular layer $=4$, multiple mucosal defects to muscular layer $=5$, mucosal defects to tunica serosa $=6$.

The level of serotonin in the gastrointestinal mucosa was also determined biochemically by Bogdanski's method (7) in the same preparation used for histochemical localization of monoamines.

\section{RESULTS}

1. Cellular localization of serotonin and norepinephrine in the gastrointestinal tract in normal cats In the duodenum and pyloric region many cells in the mucosal epithelium showed intense yellow fluorescence and in the cardia and corpus some cells in the mucosal epithelium also showed similar fluorescence. When the preparation was immersed in water or

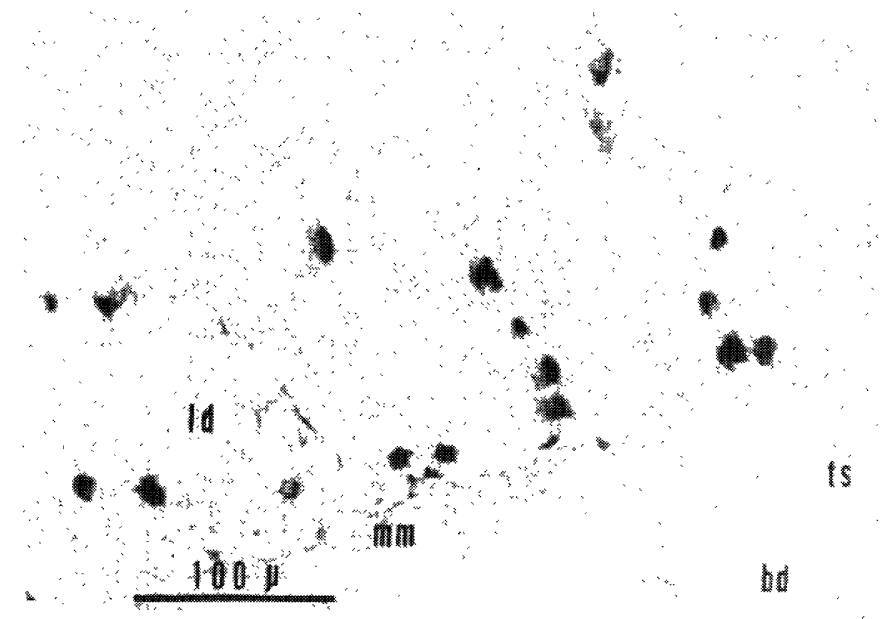

Fig. 1. Section of the duodenum of a non-treated cat. Many cells with intense fluorescence are seen in the bottom of the intestinal glands (ld). No fluorescence is seen in Brunner's glands (bd) in the submucosa (ts). $\mathrm{mm}$ : lamina muscularis mucosae $\times 150$. 


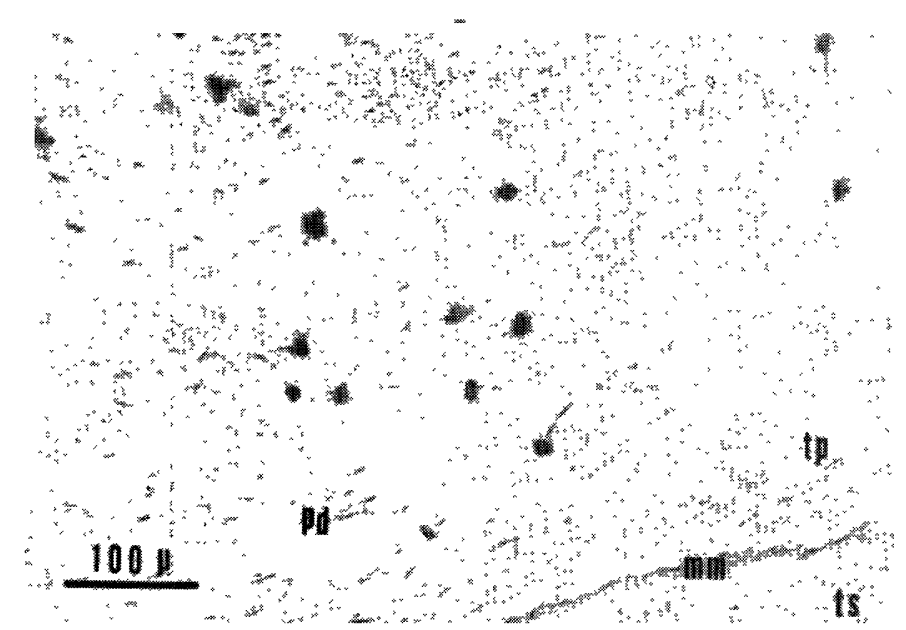

Fig. 2. Section of the pyloric region of a non-treated cat. Fluorescent cells are seen between the intermediary portion and bottom of the pyloric glands (pd). tp : lamina propria mucosae $\times 100$.

in a dilute solution of sodium borohydride the fluorescence immediately disappeared. This indicated that the yellow fluorescence is a specific identification of the presence of serotonin (8). Norberg (9) has observed cells with similar yellowish fluorescence in the rat intestine and he referred to them as enterochromaffine cells containing serotonin.

In the duodenum serotonin containing cells were mainly seen in the bottom of the intestinal glands (Fig. 1). Sometimes they could be seen in the intermediary part and also in the neck region. The number of serotonin containing cells was always less than one-fourth of all cells present in the intestinal glands. In the pyloric region the number of serotonin containing cells was somewhat less than that in the duodenum. They were mainly seen in the region between the intermediary portion and the bottom of the pyloric glands (Fig. 2). A similar location of serotonin containing cells was seen in the cardia and corpus but they were very scarce (Fig. 3). The level of serotonin in the duodenum, pylorus, corpus

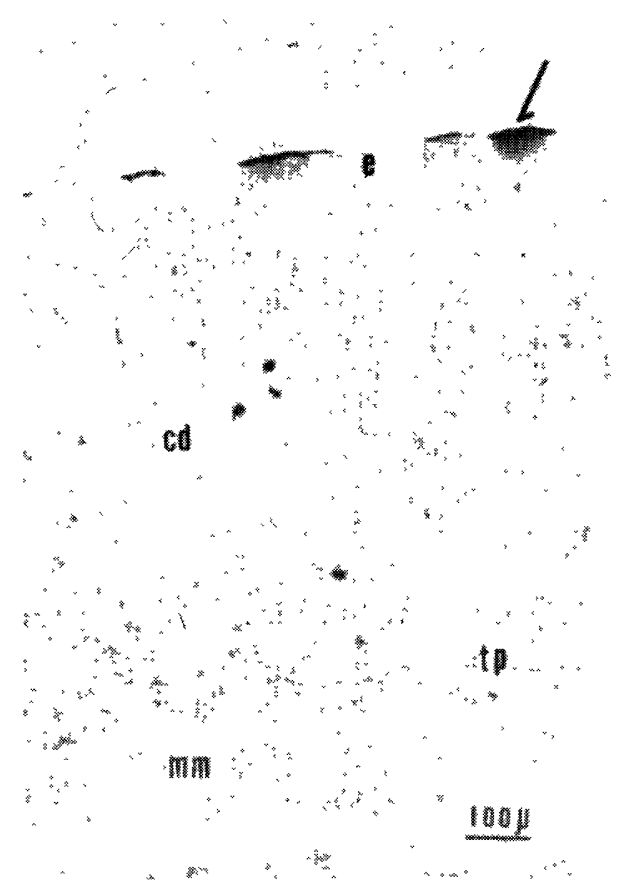

Fig. 3. Section of the corpus of a non-treated cat. A few cells with fluorescence are seen in the gastric glands (cd). Autofluorescence is seen along the epithelium of villı(e) which was not extinguished by 1 mmersion in water or a solution of sodium borohydride. $\times 50$. 
and cardia was $1.16,0.96,0.71$ and $0.70 \mu \mathrm{g} / \mathrm{g}$ wet weight, respectively.

In the mast cells which usually surround the blood vessels in the submucosa no fluorescence was seen.

Usually in the submucosa, and rarely in the lamina propria mucosa, blood vessels were seen with networks of intense green to yellow-green fluorescence. This indicates the presence of adrenergic nerve terminals as already described by many authors $(10,11)$.

\section{Pathological and histochemical changes}

\section{1) Effect of reserpine}

Twenty-four hours after the subcutaneous administration of reserpine in doses of 0.05 , $0.1,0.5,1.0$ and $3.0 \mathrm{mg} / \mathrm{kg}$, the gastrointestinal tract was autopsied and examined by histochemical methods. Haemorrhagic erosions and mucosal defects of about $1 \mathrm{~mm}$ in diameter were seen in the pyloric region and erosions were also seen in the duodenum in 2 out of 4 animals which had been administered $0.1 \mathrm{mg} / \mathrm{kg}$ of reserpine (Fig 4). Two

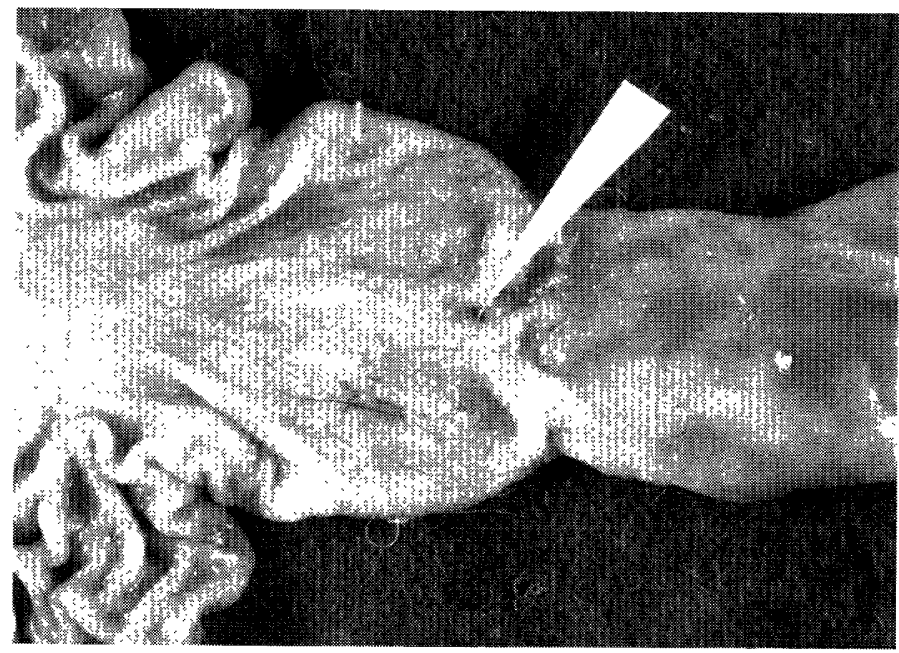

FIG. 4. Pyloric region (left) and duodenum (right) 24 hours after administration of $0.1 \mathrm{mg} / \mathrm{kg}$ of reserpine. Haemorrhagic erosion and small ulcers are seen.

TABLE 1. Grade of ulcers produced by reserpine and grid shock.

\begin{tabular}{|c|c|c|c|c|c|c|}
\hline \multirow{2}{*}{ Group No. } & \multirow{2}{*}{ Procedure } & \multirow{2}{*}{$\begin{array}{c}\text { Number } \\
\text { of cats }\end{array}$} & \multicolumn{4}{|c|}{ Grade of ulcer } \\
\hline & & & Corpus & Pylorus & Duodenum & Total \\
\hline I & Non-treated & 3 & 0 & 0 & 0 & 0 \\
\hline II & $24 \mathrm{hr}$ & 4 & 0.5 & 0.3 & 1.5 & 2.3 \\
\hline III & WIIIIIIIIIIII/, 24 hr "TIIIIIIIIIIII/A & 4 & 0.5 & 0 & 0.5 & 1.0 \\
\hline IV & $\downarrow 20 \mathrm{hr} \quad$ WIIIIII, $4 \mathrm{hr}$ WIIIII// & 4 & 0.8 & 3.3 & 2.8 & 6.9 \\
\hline $\mathrm{V}$ & $\begin{array}{l}\text { Similar to IV, N. vagus } \\
\text { and splanchnicus were } \\
\text { cut }\end{array}$ & 4 & 0 & 1.0 & 0.5 & 1.5 \\
\hline
\end{tabular}

$\downarrow$ : subcutaneous injection of $0.1 \mathrm{mg} / \mathrm{kg}$ of reserpine, WIIIIIIIIIIII// : grid shock 
animals showed no macroscopical changes in either the stomach or duodenum. Reserpine in the dose of more than $0.5 \mathrm{mg} / \mathrm{kg}$ produced erosions and mucosal defects in all animals and $3 \mathrm{mg} / \mathrm{kg}$ of reserpine produced severe defects penetrating down to the submucosa. The severity of ulceration produced by reserpine was graduated as described in the method section and is summarized in Table 1.

Fluorescences found in enterochromaffine cells and also in nerve terminals decreased or disappeared 24 hours after reserpine treatment. This suggests that serotonin in enterochromaffine cells and norepinephrine in the nerve terminals were released by reserpine and metabolically destroyed. The minimum dosage of reserpine which could cause a detectable decrease of the intensity of fluorescence and the number of serotonin containing

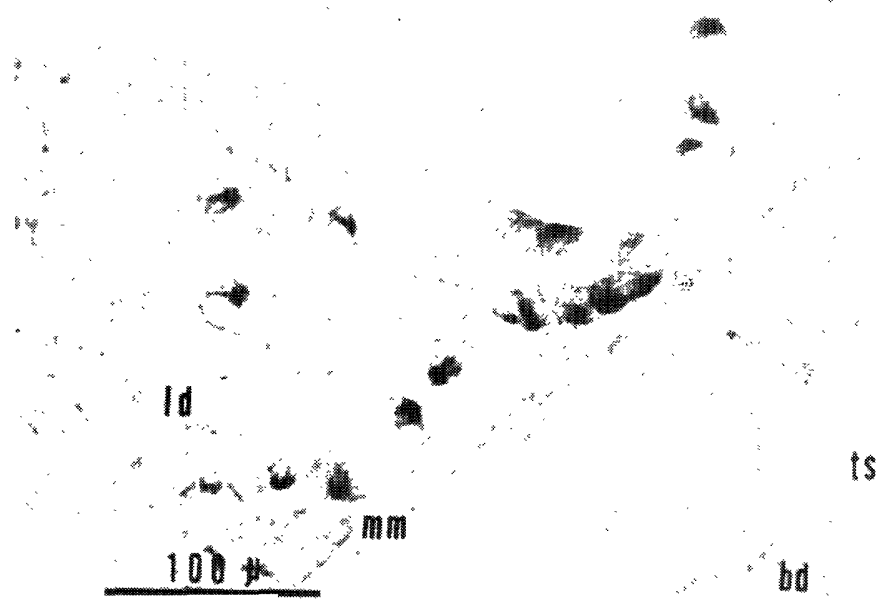

FIG. 5. Section of the duodenum of the same cat as that shown in Fig. 4. Number and intensity of fluorescent serotonin containing cells are not markedly decreased. $\times 150$.

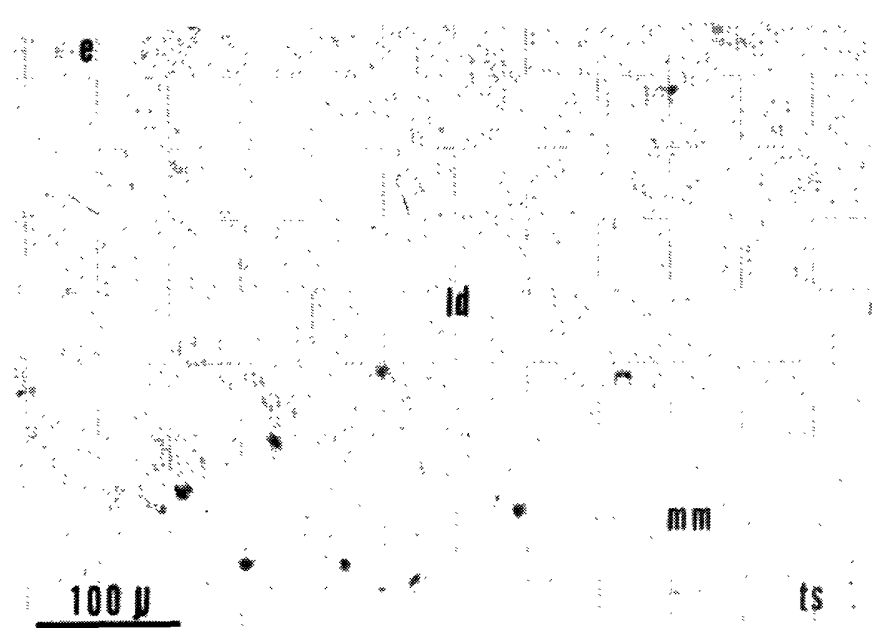

FIG. 6. Section of duodenum of reserpine treated cat $(1 \mathrm{mg} / \mathrm{kg})$. Fluorescent cells have disappeared considerably. $\times 100$. 
cells was about $0.5 \mathrm{mg} / \mathrm{kg}$. On the other hand green fluorescence in the nerve terminals was extinguished almost completely by $0.1 \mathrm{mg} / \mathrm{kg}$ of reserpine, by which cells with yellow fluorescence were not significantly reduced as shown in Fig. 5. Fig. 6 shows the disappearence of yellow fluorescence from cells when the animals was given $1 \mathrm{mg} / \mathrm{kg}$ of reserpine.

\section{2) Effect of reserpine and grid shock}

Grid shock given for 24 hours without reserpine produced only slight mucosal defects with or without hyperemia. No marked changes were seen in the intensity and number of green and yellow fluorescence in the tela submucosa and mucosal epithelial cells.

When the grid shock was given for 4 hours, 20 hours after administration of 0.1 $\mathrm{mg} / \mathrm{kg}$ of reserpine, sever ulcers with haemorrhage were always observed (Fig. 7). Histological examination of these ulcers showed that the lesion had penetrated down to the lamina muscularis mucosa and tela submucosa.

Histochemical fluorescent microscopic examination of these tissues revealed that serotonin in the epithelial cells of the duodenum was markedly decreased but in the stomach the decrease of fluorescence was less marked. In the duodenum decrease in the intensity of fluorescence was also accompanied by a decrease in the number of cells with fluorescence in about two-thirds of the non-treated animals (Fig. 8). This observation agrees well with the biochemical estimation of serotonin which showed that in the duodenum the level of serotonin was reduced to $44 \%$ in the normal animals while in the stomach reduction was only $6 \%$.

Green to yellow-green fluorescence of norepinephrine which was usually seen surrounding the blood vessels disappeared almost completely.

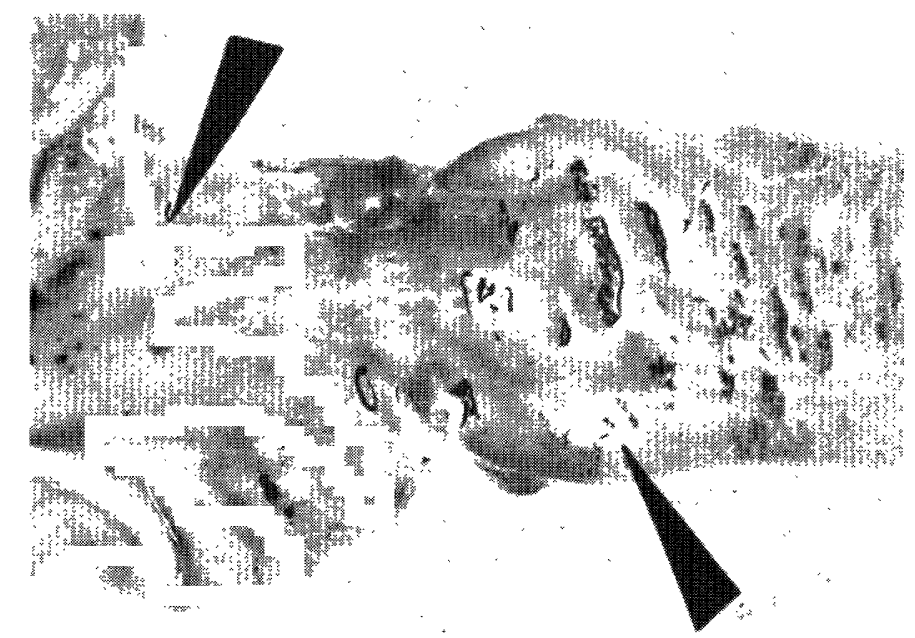

FIG. 7. Pyloric region (left) and duodenum (right) of cat given grid shock for 4 hours, 20 hours after administration of $0.1 \mathrm{mg} / \mathrm{kg}$ of reserpine. Dotted haemorrhages and severe ulcers are seen in both the pyloric region and duodenum. 


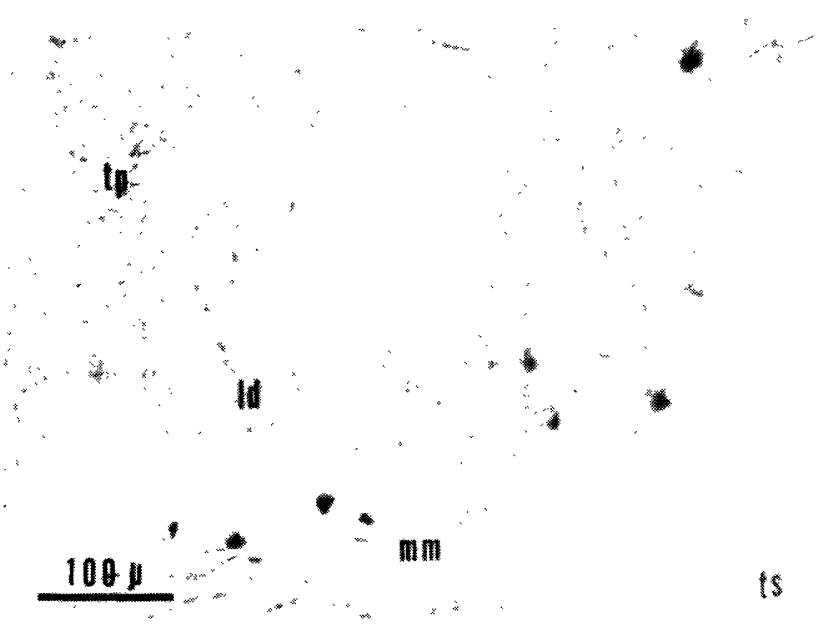

FIG. 8. Section of duodenum of the same cat as that shown in Fig. 7. Fluorescent cells are very few compared with a non-treated cat. $\times 100$.

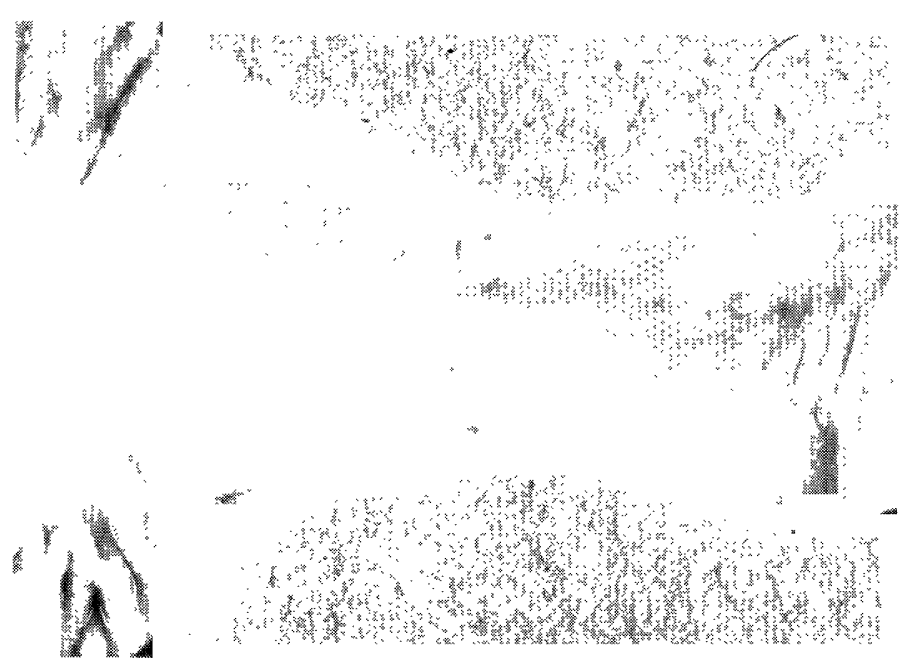

FIG. 9. Pyloric region and duodenum of vagotomized and splanchnectomized cat, which has been given reserpine and grid shock in the same schedule as that shown in Fig. 7. Production of ulcers has been prevented almost completely.

Bilateral vagotomy at the cervical level and splanchnectomy markedly decreased ulcer formation by grid shock combined with pretreatment of reserpine (Fig. 9). The histochemical observations of the gastrointestinal tracts of these animals showed a decrease in fluorescence in the epithelial cells of the stomach and duodenum which was very similar to that of animals without these operations in which ulcers were produced by grid shock combined with reserpine. The grade of ulceration is summarized in Table 1.

\section{DISCUSSION}

In this report the distribution of serotonin containing cells and also norepinephrine containing adrenergic nerve endings in the gastrointestinal wall of the normal cats by 
means of fluorescence microscopy was described. An attempt was made to correlate changes in the amount of both amines in the gastrointestinal tissues to the formation of experimental ulcers.

As already reported by Norberg (9), many cells in the epithelial glands of the gastrointestinal tract of normal cats contain serotonin which was located by an intense yellow fluorescence (see methods). However, they were not uniformally distributed in the gastrointestinal tract. The duodenum showed the highest concentration and lesser amounts appeared in the pyloric region, corpus and cardia, respectively. In the last two regions serotonin containing cells were very rare.

Gregg (12) has shown that in the rat the argentaffin cells are restricted to and evenly distributed over the antrum, lying usually in the basal third of the mucosal cells, and are scarcely found in the duodenum and corpus. Norberg (9) has also shown that in rat intestine the number of serotonin containing enterochromaffine cells are small. On the other hand, in the present study it was found that in the cat gastrointestinal tract many cells contained serotonin and this was most conspicuous in the duodenum. It is noteworthy that ulcers could not be formed in rat duodenum by the combined action of reserpine and stess (13).

In the cat serotonin was found mainly in the mucosal epithelium in the gastrointestinal tract and not in the tela submucosa and tunica muscularis by the present histochemical methods. Similar observation was reported by Feldberg and Toh (15) in the dog and rabbit. Norberg (10) has shown that mast cells in the connective tissue in rat sublingual and submaxillary glands contained serotonin. In mast cells found in the submucosa of the gastrointestinal tract of the cat, yellow fluorescence of serotonin was not seen. The details will be described elsewhere.

Thought it is a fact that decrease in the serotonin contents by reserpine administration is less marked in the gastrointestinal tract than in other tissues (16), large doses of reserpine (more than $1 \mathrm{mg} / \mathrm{kg}$ ) always resulted in a marked decrease in the number of serotonin containing cells in the pyloric region and in the duodenum. A decerase in the number of serotonin containing cells in both parts of the cat gastrointestinal tract depended on the dosage of reserpine administered.

On the other hand, administration of large doses of reserpine gave rise to severe ulcer formation in the cat gastrointestinal tract, mainly in the pyloric region and duodenum. Severe ulcers, in number, scale and depth of lesion, were found when a small dose $(0.1 \mathrm{mg} / \mathrm{kg})$ of reserpine was combined with external stress such as a continuous electrical shock from the floor grids. Controlled experiments showed that neither alone failed to produce severe ulcers. At the same time, a small dose of reserpine $(0.1 \mathrm{mg} / \mathrm{kg})$ or electrical shock alone hardly influenced the serotonin contents of the mucosal epithelium. However, when the two were combined a marked decrease in mucosal serotonin was observed. These findings suggest that the ulcer formation reported in this paper involves at least two factors; namely, release of serotonin by reserpine and external stress inflicted on the animals. According to Kido (4), the external stress had to be given after the release 
of serotonin to produce severe ulcers. Blackman (17) also described that reserpine-like drugs caused gastric haemorrhage by a mechanism involving liberation of serotonin. However, results of bilateral vagotomy and splanchnectomy introduced a complication because no ulcer was found in the operated animals even when mucosal serotonin was considerably exhausted (which caused severe ulcers in the non-operated animals). To explain this fact it is suggested that external stress such as grid shocks has two different effects in ulcer formation. External stress, on the one hand, enhances serotonin release by reserpine and this exhaustion of serotonin lowers the resistance of mucosal tissue against aggression. On the other hand, external stress may also act on the autonomic center such as the hypothalamus and this may give rise to an increase in the activities of such nerves as N. vagus and N. splanchnicus which innervate the gastrointestinal wall. Electrical shocks from the floor grids yield a rage reaction which is very similar to that obtained by electrical stimulation of the ventromedial nucleus of hypothalamus. This fact seems to give support to hypotheses on the mode of action of external stress. However this has to be proved by further experimentation.

Imipramine prevents ulcer formation by reserpine (18), and syrosingopine has different ulcerogenic activities from that of reserpine $(17,19)$. These findings suggest that drugs such as reserpine may produce ulcers through central as well as peripheral action.

Norepinephrine, usually found in the vasoconstrictive nerve terminal, is also thought to play an important role in the formation of ulcers in the gastrointestinal tract. Nicoloff (20) has shown that norepinephrine given into the gastric artery produced ulcers only when active gastric secretion was present. He concluded that the cause of the gastric ulcer was ischemia by the vasoconstrictive action of norepinephrine. Histological examination of the ulcers produced in the present experiment showed the presence of marked dilation and congestion of blood vessels in the submucosa around the damaged area. This might have caused a circulatory disorder which could be attributed to the disappearence of norepinephrine in the vasoconstricting nerve endings.

\section{SUMMARY}

A decrease in the amount of mucosal monoamines such as serotonin and norepinephrine were correlated to ulcer formation in the gastrointestinal tract of cats. Monoamines were estimated by histochemical (fiuorescence microscopy) as well as biochemical methods. Serotonin containing enterochromaffine cells were found frequently in the intestinal and pyloric glands and rarely in the gastric glands. The amount of serotonin was not influenced by either small doses of reserpine or external stresses such as grid shocks. Either of them failed to produce ulcers. However when the two were combined serotonin containing cells disappeared and severe ulcers resulted. Vagotomy and splanchnectomy prevented ulcer formation though did not prevent release of serotonin by reserpine and grid shocks.

It is suggested that ulcer formation involves central as well as peripheral factors; reserpine and external stress reduce tissue monoamines which lowers the resistance of the 
mucosa to aggression, and centrally the stress may give rise to an increase in the activities of the autonomic nerve which is necessary to produce ulcers.

Acknoweledgment: The author thanks Prof. K. Shimamoto and Dr. M. Fujiwara of the Department of Pharmacology, Kyoto University, for their kind guidance and advice in the histochemical studies and Dr. T. Ito of Osaka Prefectural Medical Center for his useful support in the biochemical assays. Thanks are also given to Dr. R. Kido for his guidance through the studies.

\section{REFERENCES}

1) Hartry, A.L.: J. comp. physiol. Psychol. 55, 719 (1962)

2) Sawrey, J.M. ANd SAwrey, W.L.: Ibid. 57, 307 (1964)

3) Nishizaki, H., Yамamoto, K. and Kido, R.: Folia pharmacol. japon. 60, $146 \S$ (1964)

4) KIDo, R.: Brain and Nerve 19, 467 (1967)

5) Carlsson, A., Falck, B. and Hillarp, N.-Å.: Acta physiol. scand. 56, Suppl. 196 (1962)

6) Falck, B. and Owman, C.: Acta Univ. Lund. II, No. 7 (1965)

7) Bogdanski, D.F., Pletscher, A., Brodie, B.B. And Udenfriend, S.: J. Pharmac. exp. Ther. 117, 82 (1956)

8) Corrodi, H., Hillarp, N.-A. and Jonsson, G.: J. Histochem. Cytochem. 12, 582 (1964)

9) Norberg, K.-A.: Int. J. Neuropharmac. 3, 379 (1964)

10) Norberg, K.-A. And Hamberger, B.: Acta physiol. scand. 63, Suppl. 238 (1964)

11) Fujiwara, M., Tanaka, C., Honjo, T. and Okegana, T.: This Journal 15, 369 (1965)

12) GregG, R.V.: J. Morph. 119, 81 (1966)

13) Yamamoto, K. and Kimura, Y.: to be published

14) West, G.B.: J. Pharm. Pharmac. 10, 92T (1958)

15) Feldberg, W. and Toh, C.C.: J. Physiol. 119, 352 (1953)

16) Garattini, S. and Valzelli, L.: Serotonin, p. 82, Elsevier Publishing Comp., Amsterdam (1965)

17) Blackman, J.G., Campion, D.S. and Fastier, F.N.: Br. J. Pharmac. Chemother. 14, 112 (1959)

18) Domenjoz, R. and Theobald, W.: Archs int. Pharmacodyn, Thér. 20, 450 (1950)

19) Doteuchi, M.: to be published

20) Nicoloff, D.M., Peter, E.T., Leonard, A.S. and Wangensteen, O.H.: J. Am. med. Ass. 191, 383 (1965) 